\title{
West Palaearctic species of the genus Diostracus Loew, 1861 (Diptera: Dolichopodidae)
}

\author{
Igor Ya. GRICHANOV \\ All-Russian Institute of Plant Protection, Podbelskogo 3, St.Petersburg, Pushkin, 196608, Russia \\ E-mail: grichanov@mail.ru \\ urn:1sid:zoobank.org:author:5320AD3A-92D8-4820-8091-24802F8C8C06
}

\begin{abstract}
A new status (as subgenera of Diostracus Loew, 1861) for Sphyrotarsus Mik, 1874, Lagodechia Negrobov \& Tsurikov, 1996 and Ozmena Özdikmen, 2010 stat. nov. is proposed. A new species, Diostracus (Sphyrotarsus) kustovi sp. nov., is described from the Russian Caucasus. The following recombinations (comb. nov.) are also proposed: Diostracus (Sphyrotarsus) argyrostomus (Mik, 1874); D. (S.) caucasicus (Negrobov, 1965); D. (S.) hervebazini (Parent, 1914); D. (S.) hessei (Parent, 1914); D. (S.) hygrophilus (Becker, 1891); D. (S.) leucostomus (Loew, 1861); D. (S.) parenti (Hesse, 1933); D. (Lagodechia) spinulifer Negrobov \& Tsurikov, 1988; and D. (Ozmena) stackelbergi (Negrobov, 1965). A key to ten Diostracus species inhabiting the West Palaearctic Region is provided.
\end{abstract}

Key words. Dolichopodidae, Diostracus, West Palaearctic, new species, key.

Grichanov I.Ya. 2013. West Palaearctic species of the genus Diostracus Loew, 1861 (Diptera: Dolichopodidae). European Journal of Taxonomy 61: 1-14. http://dx.doi.org/10.5852/ejt.2013.61

\section{Introduction}

Until the 1960s the genus Diostracus Loew, 1861, belonging to the subfamily Hydrophorinae, had long been supposed to be Nearctic in distribution, with three known species. In 1968 it was recorded from East Asia for the first time by Takagi (1968). To date, 85 species have been described from a vast territory of the East Palaearctic and Orient, from Buryatia and Sakhalin in the north to Nepal, Bhutan, Assam, NE Myanmar, Yunnan and Taiwan in the south (Grichanov 2003-2013). Negrobov (1978) placed the genus Asphyrotarsus Oldenberg, 1916 in synonymy with Diostracus, thus recording the genus in the West Palaearctic for the first time. In all, the Palaearctic Region is known to include 21 of the 88 known species of Diostracus (Grichanov et al. 2011b).

The adults are usually found on wet rocks in mountainous areas or on stones in streams and waterfalls at high altitude. A key to Palaearctic species of the genus was provided by Negrobov (1978). A key to 37 Nepalese species was given by Saigusa (1984), who proposed 12 species groups and subgroups. A key to 14 Japanese species was given by Masunaga (2000), who mentioned some more species groups. The last key to males of the 23 known Chinese species was published by Yang et al. (2011).

A new species, Diostracus (Sphyrotarsus) kustovi sp. nov., from the Russian Caucasus is here described and illustrated. The following recombinations (comb. nov.) are also proposed: Diostracus (Sphyrotarsus) 
argyrostomus (Mik, 1874); D. (S.) caucasicus (Negrobov, 1965); D. (S.) hervebazini (Parent, 1914); D. (S.) hessei (Parent, 1914); D. (S.) hygrophilus (Becker, 1891); D. (S.) leucostomus (Loew, 1861); D. (S.) parenti (Hesse, 1933); D. (Lagodechia) spinulifer Negrobov \& Tsurikov, 1988; and D. (Ozmena) stackelbergi (Negrobov, 1965). In addition, a key to males of West Palaearctic species is provided. With the new species described here, the West Palaearctic fauna of Diostracus now totals 10 species.

\title{
Material and Methods
}

The holotype and paratype of the new species as well as other material examined are housed at the Zoological Institute of the Russian Academy of Sciences, St Petersburg (ZIN).

Specimens were studied and photographed with a ZEISS Discovery V-12 stereo microscope and an AxioCam MRc5 camera. Morphological terminology and abbreviations follow Cumming \& Wood (2009). The lengths of the podomeres are given in millimetres. Body length is measured from the base of the antenna to the tip of abdominal segment 7 . Wing length is measured from the base to the wing apex. Male genitalia were macerated in $10 \% \mathrm{KOH}$. The figure showing the male genitalia in lateral view is oriented as they appear on the intact specimen, with the morphologically ventral surface of the genitalia facing up, dorsal surface down, anterior end facing right and posterior end facing left. Information on world distribution for known species follows Grichanov (2003-2013).

\section{Results}

\author{
Class Hexapoda Blainville, 1816 \\ Order Diptera Linnaeus, 1758 \\ Suborder Brachycera Schiner, 1862 \\ Superfamily Empidoidea Latreille, 1804 \\ Epifamily Dolichopodoidae Latreille, 1809 \\ Family Dolichopodidae Latreille, 1809 \\ Subfamily Hydrophorinae Lioy, 1864
}

Genus Diostracus Loew, 1861

\section{Diagnosis}

The genus is very polymorphic and characterized by the following combination of characters: body dark and stout, medium- to large-sized; palpus usually enlarged, loosely applied on proboscis; proboscis bulky; antennal scape glabrous or setose dorsally; arista-like stylus usually dorsal, sometimes basodorsal or subapical to apical; posterior mesonotum flattened; acrostichal setae absent; 4-6 dorsocentral bristles variable in length; sutural and postsutural, some notopleural, supra-alar and post-alar bristles sometimes absent or reduced; scutellum with 1-2 pairs of strong bristles and with some short lateral setae or hairs, sometimes with three pairs of long bristles; mid and hind coxae without bristle on the outer side; legs often modified; tarsi with more or less modified empodium and claws, usually without pulvilli; wing elongate and wide, sometimes modified in males; costa ended beyond tip of wing; crossvein $\mathrm{dm}$-cu longer than distal section of $\mathrm{CuA}_{1}$ vein, sometimes strongly sinuate; $\mathrm{M}_{1+2}$ usually slightly convex anteriorly, often irregularly curved, more or less parallel to $\mathrm{R}_{4+5}$, at least partly behind $\mathrm{dm}$-cu.

\section{Remarks}

The genus Sphyrotarsus Mik, 1874 includes 5 species from the European Alps, one Caucasian species and one Pamiran species. It was diagnosed by scape glabrous dorsally; tarsi with reduced empodium and without pulvilli; $\mathrm{M}_{1+2}$ and $\mathrm{R}_{4+5}$ are not strictly parallel to each other (Parent 1938); scutellum with 
3 pairs of bristles (Negrobov 1978). Furthermore, the Pamiran subgenus Takagia Negrobov, 1973 (of Sphyrotarsus), was diagnosed by elongated antennal postpedicel with arista apical, somewhat widened at apex in male; sutural bristle absent; one supra-alar bristle; scutellum with 2 pairs of bristles (Negrobov 1973, 1978). Nevertheless, all these characters are rather variable and can be found in East Asian species of Diostracus. The monotypic Caucasian genus Lagodechia Negrobov \& Tsurikov, 1996 was diagnosed also by variable characters of face, mesonotal setation, wing venation and morphology of abdomen (Negrobov \& Tsurikov 1996). In addition, some characters of $L$. spinulifera were incorrectly described, as follows from the illustrations published by Grichanov et al. (2011a, b). I think the diagnostic characters of these taxa have low generic significance and regard Lagodechia, Sphyrotarsus and Takagia (now Ozmena Özdikmen, 2010) as subgenera of Diostracus. Accepting a new concept of the genus, I associate 97 species with Diostracus, of which 64 occur in the Oriental Region, 30 in the Palaearctic and 3 in the Nearctic Region. The flies of the genus are all torrenticolous in habitat.

\section{Subgenus Diostracus Loew, 1861}

Diostracus Loew, 1861a: 43; Takagi 1968: 35 (diagnosis), 51 (redescription of type species). Grichanov et al. 2011b: 22 (diagnosis).

Asphyrotarsus Oldenberg, 1916: 193. — Negrobov 1978: 406 (synonym of Diostracus Loew, 1861). Type species: Liancalus leucostomus Loew, 1861 (original designation).

\section{Diagnosis}

At present the nominotypical subgenus differs from other subgenera in having a dorsally setose antennal scape. It is worth noting that many Asian Diostracus species were described with a glabrous scape (e.g., Saigusa 1984, 1995; Saigusa et al. 1997; Yang et al. 2011).

\section{Type species}

Diostracus prasinus Loew, 1861 (by monotypy).

Diostracus (Diostracus) leucostomus (Loew, 1861)

Liancalus leucostomus Loew, 1861b: 348.

Thinophilus nigripes Strobl, 1898: 219. - Negrobov 1973: 1518 (synonym of Asphyrotarsus leucostomus, redescription of type). - Type locality: Styria, Sirbitzkogel, Austria.

Asphyrotarsus leucostomus - Oldenberg 1916: 193. — Parent 1938: 312.

Diostracus leucostomus - Negrobov 1978: 411.

Diostracus nigripes - Negrobov 1978: 411.

\section{Type locality}

Kärnthen, Austria.

\section{Distribution}

Austria, France, Italy, Switzerland.

Subgenus Lagodechia Negrobov \& Tsurikov, 1996, stat. nov.

Lagodechia Negrobov \& Tsurikov [as Zurikov], 1996: 632. — Grichanov et al. 2011b: 23 (diagnosis). 


\section{Diagnosis}

Describing a new genus, Negrobov \& Tsurikov (1996) listed diagnostic characters that can be found in many Diostracus species (e.g., Saigusa 1984, 1995; Saigusa et al. 1997; Yang et al. 2011). The following characters of generic importance were listed in the original description of Lagodechia, but were not obvious on pictures made by O. Selivanova from type material (Grichanov et al. 2011a, b): antennal scape has dorsal projection; distance between scutellum and $1^{\text {st }}$ tergum is 3 times as long as scutellum. Negrobov \& Tsurikov (1996) also found important differences in the female oviscapt of Lagodechia spinulifera and Diostracus subalpinus (Negrobov, 1973). Unfortunately, D. subalpinus (described from the Baikal Lake environs) is the only Diostracus species with illustrated female genitalia. The status of D. subalpinus and D. spinulifer needs further clarification.

\section{Type species}

Diostracus spinulifer Negrobov \& Tsurikov, 1988 (original designation).

Diostracus (Lagodechia) spinulifer Negrobov \& Tsurikov, 1988, comb. nov.

Diostracus spinulifer Negrobov \& Tsurikov [as Zuricov] in Negrobov et al., 1988: 215.

Lagodechia spinulifer - Negrobov \& Tsurikov 1996: 632.

\section{Type locality}

Lagodekhis-Khevi river, upper stream, Lagodekhi Reserve, Georgia.

\section{Distribution}

Georgia.

Subgenus Ozmena Özdikmen, 2010, stat. nov.

Ozmena Özdikmen, 2010: 265 (new name for Takagia Negrobov, 1973, not Matsumura, 1942) (as subgenus of Sphyrotarsus Mik, 1874).

Takagia Negrobov, 1973: 1520 (as subgenus of Sphyrotarsus Mik, 1874) (not Matsumura, 1942). Negrobov 1978: pl. CLXI (as genus, in error). - Type species: Sphyrotarsus stackelbergi Negrobov, 1965 (original designation).

\section{Diagnosis}

The main diagnostic character of the subgenus is the elongate antennal postpedicel in both male and female, and the apical stylus (Negrobov 1973). Nevertheless, some Oriental Diostracus species also have an elongate postpedicel and an apical or subapical stylus (e.g., Saigusa 1984; Yang et al. 2011). Unfortunately, there are practically no publications with pictures of female antennae in Diostracus species.

\section{Type species}

Sphyrotarsus stackelbergi Negrobov, 1965 (by monotypy).

Diostracus (Ozmena) stackelbergi (Negrobov, 1965), comb. nov.

Sphyrotarsus stackelbergi Negrobov, 1965: 441.

Sphyrotarsus (Takagia) stackelbergi-Negrobov 1978: 405.

Sphyrotarsus (Ozmena) stackelbergi - Özdikmen 2010: 265. 
Type locality

Gorno-Badakhshan region, Khorog, river Gunt, Shugnan, Tajikistan.

\section{Distribution}

Tajikistan (Pamir).

Subgenus Sphyrotarsus Mik, 1874, stat. nov.

Sphyrotarsus Mik, 1874: 342. — Grichanov et al. 2011b: 25 (diagnosis).

\section{Diagnosis}

As presently defined, the subgenus differs from other subgenera in the presence of 6 (vs. 2-4) long bristles on the scutellum in addition to the glabrous antennal scape (Negrobov 1973; Grichanov et al. 2011b). These characters are rather variable in Asian Diostracus species (e.g., Saigusa 1984, 1995; Saigusa et al. 1997; Yang et al. 2011). Parent (1938) also used variable male secondary sexual characters to distinguish Sphyrotarsus from Asphyrotarsus (=Diostracus).

\section{Type species}

Sphyrotarsus argyrostomus Mik, 1874 (by monotypy).

Diostracus (Sphyrotarsus) argyrostomus (Mik, 1874), comb. nov.

Sphyrotarsus argyrostomus Mik, 1874: 337. — Parent 1938: 298.

Sphyrotarsus (Sphyrotarsus) argyrostomus - Negrobov 1978: 402.

\section{Type locality}

Wildbadgastein, Austria.

\section{Distribution}

Austria, France, Italy, Switzerland.

Diostracus (Sphyrotarsus) caucasicus (Negrobov, 1965), comb. nov.

Sphyrotarsus caucasicus Negrobov, 1965: 440.

Sphyrotarsus (Sphyrotarsus) caucasicus - Negrobov 1978: 403.

\section{Material}

1 $\widehat{\jmath}$, Adygea, Maikop distr., Caucasian Nature Reserve, Abago Mt, alpine belt, sweeping on grass at snowfield rivulet, $2100 \mathrm{~m}, 4$ Aug. 2008, Volfov (ZIN).

\section{Type locality}

Caucasian Reserve, Cherkesskii Ridge, Russia.

\section{Distribution}

Russia (Adygea, Krasnodar). 
Diostracus (Sphyrotarsus) hervebazini (Parent, 1914), comb. nov.

Sphyrotarsus hervebazini Parent, 1914: 85; 1938: 300.

Sphyrotarsus (Sphyrotarsus) hervebazini - Negrobov 1978: 403.

Sphryotarsus (Sphyrotarsus) hervibazini - Negrobov 1991: 42 (error for hervebazini).

\section{Type locality}

Saint-Pierre-de-Chartreuse, Isère, France.

\section{Distribution}

France, Switzerland.

Diostracus (Sphyrotarsus) hessei (Parent, 1914), comb. nov.

Sphyrotarsus hessei Parent, 1914: 108; 1938: 301.

Sphyrotarsus (Sphyrotarsus) hessei - Negrobov 1978: 403.

\section{Type locality}

Arras, France.

\section{Distribution}

France, Italy.

Diostracus (Sphyrotarsus) hygrophilus (Becker, 1891), comb. nov.

Sphyrotarsus hygrophilus Becker, 1891: 286. — Parent 1938: 303.

Sphyrotarsus (Sphyrotarsus) hygrophilus - Negrobov 1978: 404.

Sphyrotarsus (Sphyrotarsus) hydrophilus - Negrobov 1978: 404 (error for hygrophilus).

\section{Type locality}

Gesäuse bei Admont, Austria.

\section{Distribution}

Austria, France, Switzerland.

Diostracus (Sphyrotarsus) parenti (Hesse, 1933), comb. nov.

Sphyrotarsus parenti Hesse, 1933: 11. — Parent 1938: 305.

Sphyrotarsus (Sphyrotarsus) parenti - Negrobov 1978: 405.

\section{Type locality}

Col du Lautaret, France.

\section{Distribution}

France. 
Diostracus (Sphyrotarsus) kustovi sp. nov.

(Figs 1A-E, 2, 3A, B)

urn:1sid:zoobank.org:act:C06CA79F-16D5-45ED-8309-8BCD4613E37C

\section{Diagnosis}

Scutellum with 3 pairs of almost equally long bristles; antennal scape bare above; male and female postpedicel about as long as high, with dorsal stylus; male $2^{\text {nd }}$ and $3^{\text {rd }}$ abdominal sterna with strong black spines; male $4^{\text {th }}$ abdominal sternum with bundle of setae; male with modified legs and simple wings.

\section{Etymology}

This species is named after the Russian dipterologist Dr. Semyon Kustov (Krasnodar).

\section{Type material}

\section{Holotype}

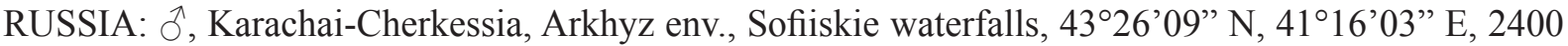
m, 03 Aug. 2012, S. Kustov (ZIN).

\section{Paratype}

RUSSIA: 19 , same data as for holotype (ZIN).

\section{Description}

\section{Male}

LeNGTH (mm). Body 9.4, wing 7.8, antenna 1.5, hypopygium 2.25 .

HEAD (Figs 1A, B). Bluish-greenish black, pollinose; clypeus shining green, weakly pollinose, 1/3 as wide as head; face about $1 / 5$ as wide as head, almost as long as wide; ocellar bristles strong, vertical and postvertical bristles about $1 / 2$ as long as ocellar bristle; postocular ciliation black, strong, nearly as long as postvertical on upper $1 / 2$, finer and yellowish below; ventral $1 / 2$ of postcranium clothed with many long yellow hairs, some of which as thick as vertical bristle; antenna with bare vase-like scape; pedicel with ring of short setae; postpedicel as long as high, rounded distally, with middorsal simple arista-like stylus; length $(\mathrm{mm})$ of scape to pedicel to postpedicel to stylus ( $1^{\text {st }}$ and $2^{\text {nd }}$ segments), 0.16-0.11-0.20.13-0.85; palpus ovate, 1.6 times as long as wide, $1 / 3$ as long as eye height, slightly dilated at middle; palpus black in ground colour, glittering silvery by pollinosity, bearing short black setae on outer side and along margin; proboscis moderately large for the genus.

THorax. Greenish black, with washed pollinosity; mesonotum with pair of blackish longitudinal stripes; acrostichals absent; 5-6 asymmetrical dorsocentrals; 1 humeral with 1-2 short setae in front, 1 posthumeral, 2 notopleurals, 1 sutural, 1 postsutural, 1 supra-alar, 1 postalar; scutellum with 3 pairs of strong scutellars, of which outer pair 2/3 length of median 4 bristles; proepisternum with about 10 yellow setae on its lower portion and with about 6 similar seta on its upper portion; scutellum about 3 times wider than long; postscutellum about 3 times as long as scutellum (similar to that in D. leucostomus).

LEGS. Rather long, black with slight greenish or bluish tinge on coxae and femora; fore coxa concave on anterior surface towards tip, there clothed with short, fine hairs, also with row of short, black, blunt setae on anterodistal margin; fore femur moderately thick, strongly curved at basal 1/3, with very short, fine hairs; fore tibia slightly thickened, bearing 4 dorsal bristles, 2 posterodorsals at base, 1 long curled posterodorsal bristle at apex, 1/3 as long as tibia, and with double row of short, erect ventral setae; fore basitarsus (Fig. 1C) constricted and almost bare in $1^{\text {st }}$ quarter, thickened in $2^{\text {nd }}$ quarter, densely short setose; its thickening 
bearing 3 long, curled dorsal bristles, half as long as basitarsus, and row of 12 short blunt spinules; $2^{\text {nd }}$ to $4^{\text {th }}$ tarsomeres simple, bearing elongate setae dorsally; $4^{\text {th }}$ tarsomere with strong apicoventral seta; $5^{\text {th }}$ segment flattened dorsoventrally; pulvillus reduced, empodium spicular, claws strong, about half as long as $5^{\text {th }}$ segment; mid coxa covered with short fine white hairs anteriorly, bearing 3-4 strong apical dirty yellow bristles forming some kind of spine; mid femur (Fig. 1D) slightly curved, distinctly emarginated dorsally along basal half or more, with rather long yellow hairs and setae on anterior, dorsal and ventral surfaces

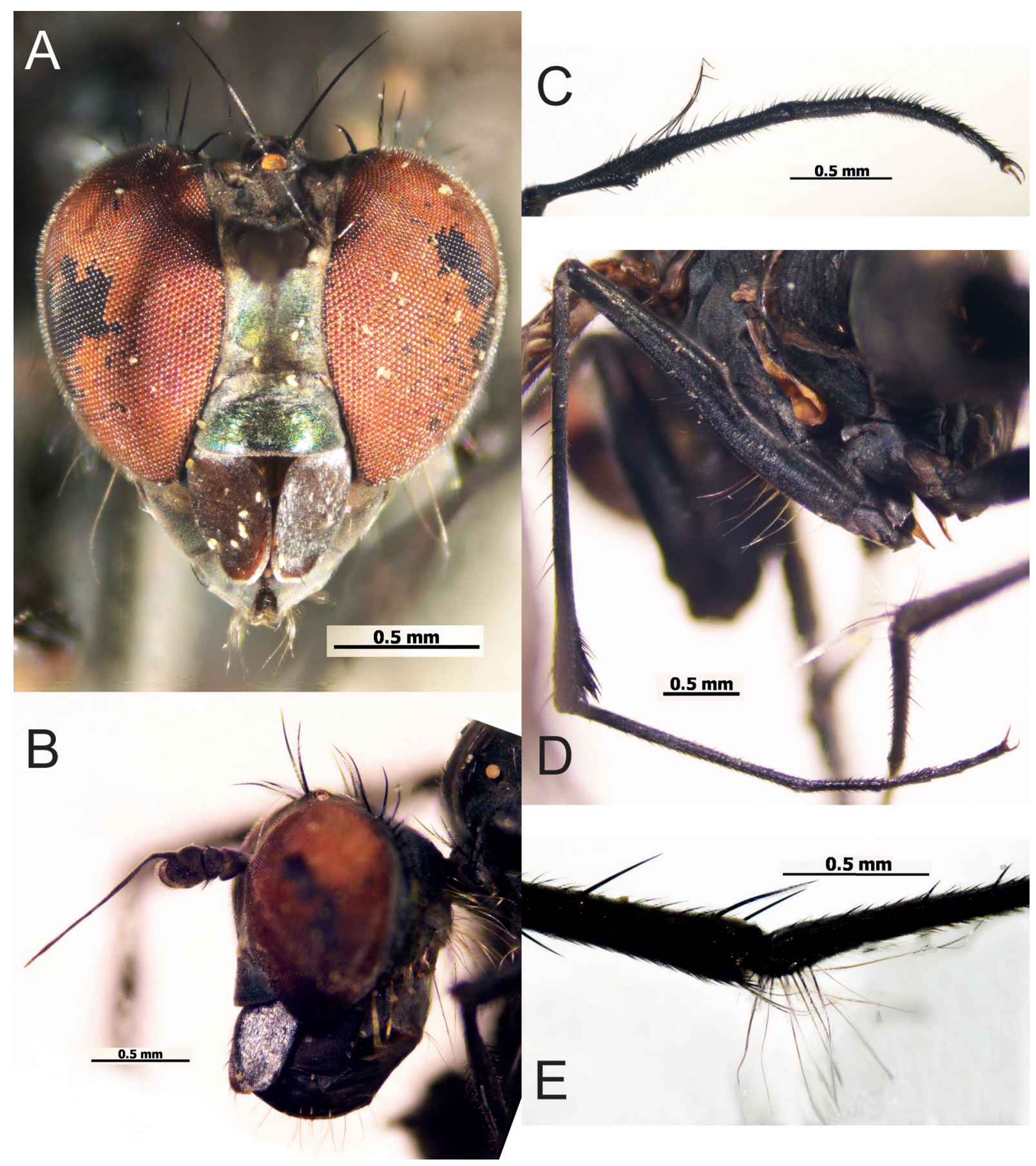

Fig. 1. Diostracus (Sphyrotarsus) kustovi sp. nov. Male holotype. A. Head in anterior view. B. Head in lateral view. C. Fore tarsus. D. Mid leg. E. Hind tibia in apical view and basitarsus. 
of its basal $1 / 2$, the vestiture slightly darker on dorsal surface; the longest setae twice as long as femur diameter; apical 1/2 of mid femur almost bare and bearing 2-3 anteroventral and 2-3 posteroventral short bristles; mid tibia straight, subapically thickened, short setose, with several anterodorsal and posterodorsal bristles and subapical ventral fringe of strong black bristles longer than tibia thickness; mid tarsus slender, simple and short setose, with reduced pulvillus and empodium; hind coxa bearing sparse short, yellow hairs outside; hind femur long and simple, only slightly curved, with about 6 fine anteroventral black setae in distal $1 / 2$, not longer than femur diameter, with long, fine, subapical anterior bristle; hind tibia slender, bearing several longish bristles on anterodorsal and posterodorsal surfaces and shorter ones on anteroventral and posteroventral surfaces, with about 5 long blackish-brown apicoventral bristles, of which longest bristle reaching middle of basitarsus; hind basitarsus (Fig. 1E) slightly swollen at base, with 4 short dorsal setae, with about 10 long blackish and brownish fine bristles at base ventrally and anteriorly, longest seta more than half as long as basitarsus; next tarsomeres slender and simple; pulvillus and empodium reduced. Fore podomere length (from femur to tarsomere 5, mm): 1.77-1.96-1.37-0.400.27-0.18-0.29 ( 0.45 with claws); mid leg: 2.86-2.95-1.65-0.54-0.33-0.23-0.33 ( 0.49 with claws); hind leg: 3.00-3.52-1.38-0.72-0.43-0.25-0.29 (0.40 with claws).

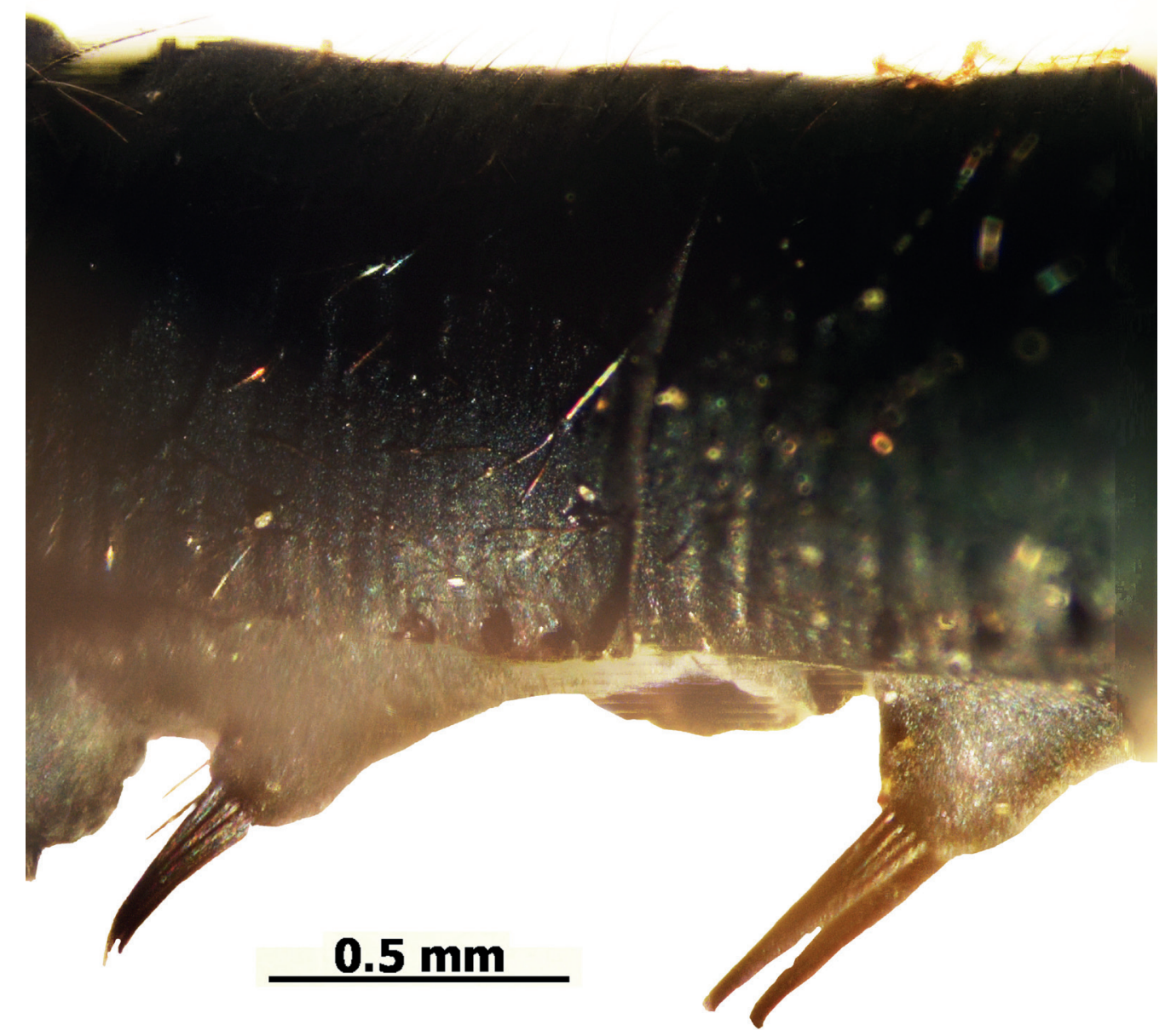

Fig. 2. Diostracus (Sphyrotarsus) kustovi sp. nov. Male holotype. Abdominal segments 2 and 3. 

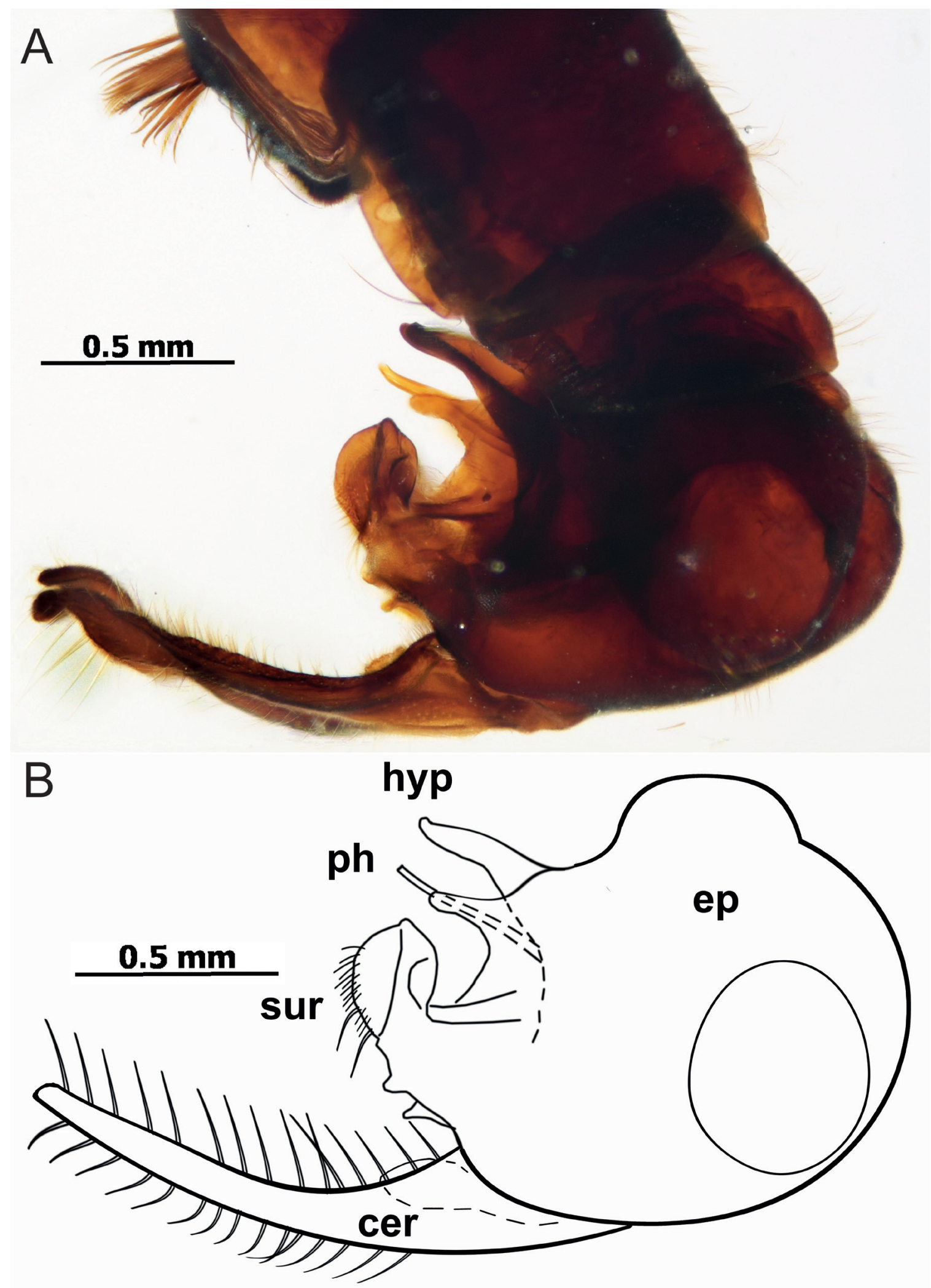

Fig. 3. Diostracus (Sphyrotarsus) kustovi sp. nov. Male holotype. A. Apex of abdomen and hypopygium. B. Hypopygium. Abbreviations: cer - cercus, ep - epandrium, hyp - hypandrium, ph - phallus, sur surstylus. 
WING. Simple, almost hyaline, with simple veins; $\mathrm{Sc}$ developed; $\mathrm{R}_{2+3}$ and $\mathrm{R}_{4+5}$ weakly convex anteriorly; $\mathrm{R}_{4+5}$ and $\mathrm{M}_{1+2}$ almost straight and parallel behind level of $\mathrm{dm}-\mathrm{cu} ; \mathrm{M}_{1+2}$ weakly sinuate; ratio of part of costa between $\mathrm{R}_{2+3}$ and $\mathrm{R}_{4+5}$ to that between $\mathrm{R}_{4+5}$ and $\mathrm{M}_{1+2}=73 / 57$; ratio of cross-vein $d m-c u$ to distal part of $\mathrm{CuA}_{1}=84 / 47 ; d m-c u$ perpendicular to both longitudinal veins; calypter blackish, with pale cilia; halter orange yellow.

AвDOMEN. Black, with washed pollinosity, with short black setae; $1^{\text {st }}$ tergum with long brownish setae and ciliated with long black bristles on posterior margin; $1^{\text {st }}$ sternum projected, with shallow transverse furrow anteriorly; $2^{\text {nd }}$ sternum (Fig. 2) with medial bulb at anterior $1 / 3$, bearing 2 adjacent black spines formed of long glued setae and directed anteriorly; $3^{\text {rd }}$ sternum (Fig. 2) with twice as large bulb bearing 2 diverging black spines formed of long glued setae and directed anteriorly; $4^{\text {th }}$ sternum (Fig. 3A) with 2 median bunches of erect brownish setae on low convection, with posterior margin somewhat projecting and covered with short hairs; hypopygium (Fig. 3B) black, moderately large, with posterodorsal portion moderately produced and rounded; hypandrium subtriangular, narrow distally and bifurcated at apex; phallus simple; epandrial lobe short and narrow; surstylus brown, almost semicircular, with short hairs dorsally; cercus distinctly longer than epandrium, slightly swollen at base, band-like, simple, densely ciliated with long yellow setae.

\section{Female}

Length (mm). Body 7.0, wing 8.0, antenna 1.4.

Similar to male except lacking male secondary sexual characters, otherwise as follows: 6 dorsocentrals of irregular length in left row and 8 dorsocentrals in right row; palpus not glittering silvery; legs and abdominal sterna simple; $6^{\text {th }}$ and $5^{\text {th }}$ terga and genital plates densely covered with fine long setae; no acanthophorites.

\section{Remarks}

Having bulbs on 2nd and 3rd sterna and bearing strong ventral spines or bunches on abdomen, the new species distinctly differs from other species of the subgenus Sphyrotarsus (see key below). $D$. (L.) spinulifer males also have a setose venter, but not bearing bulbs and thick spines. Some Chinese and Nepalese species of Diostracus were also described with male sterna ornamented with bunches of setae, spines or projections (e.g., Saigusa 1984; Yang et al. 2011), but strongly differing in many other characters.

\section{Ecology}

Both types of D. (S.) kustovi were collected together on stones at a stream (S. Kustov, pers. comm.) in high mountains at $2400 \mathrm{~m}$ above sea level.

\section{Key to West Palaearctic species of the genus Diostracus (males)}

Note: Partially based on previous keys to species of the former genus Sphyrotarsus (Parent 1938; Negrobov 1978).

1. Scutellum with 1-2 pairs of long bristles and with some short lateral setae or hairs ...........2

- Scutellum with 3 pairs of almost equally long bristles (subgenus Sphyrotarsus) .....................4

2. Scape with hairs above; 4.5-5.1 mm ............................D. (Diostracus) leucostomus (Loew, 1861)

- Scape bare above 
3. Male and female postpedicel elongate-ovate, 1.5-2 times longer than high, with apical stylus; male abdominal sternites without strong spines; body $5 \mathrm{~mm}$ long

D. (Takagia) stackelbergi (Negrobov, 1965)

- Postpedicel about as long as high, with dorsal stylus; male $2^{\text {nd }}$ to $4^{\text {th }}$ abdominal sternites with strong black spines; body 5-6.5 mm long ..............D. (Lagodechia) spinulifer Negrobov \& Zurikov, 1988

4. Male $2^{\text {nd }}$ and $3^{\text {rd }}$ abdominal sternites with strong black spines; body $7.0 \mathrm{~mm}$ (female) to 9.4 $\mathrm{mm}$ (male) long

D. (S.) kustovi sp. nov.

- Male abdominal sternites without strong spines

5. Male cercus shorter than epandrium; body $6 \mathrm{~mm}$ long .......D. (S.) caucasicus (Negrobov, 1965)

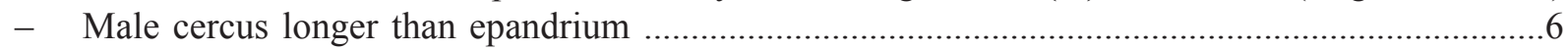

6. All tarsi with empodium scaly in male, as long as claws; mid basitarsus thin, longer than rest of tarsomeres combined; body $6.5 \mathrm{~mm}$ long

D. (S.) hygrophilus (Becker, 1891)

- Tarsi with reduced empodium; mid basitarsus shorter than rest of tarsomeres combined ........7

7. Male cercus bifurcated between base and middle; mid basitarsus thickened at middle and at

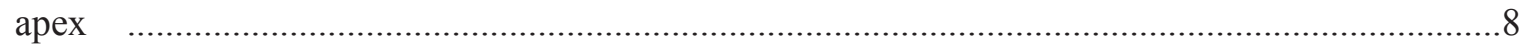

- Male cercus bifurcated at apex only; mid basitarsus simple or thickened at base .................9

8. Outer arm of cercus long and narrow; body 5.2-6 mm long .....D. (S.) argyrostomus (Mik, 1874)

- Outer arm of cercus short, broad, subtriangular; body $7 \mathrm{~mm}$ long .......D. (S.) parenti (Hesse, 1933)

9. Palpus bare; proboscis as long as head; body 5.2 long ....................... (S.) hessei (Parent, 1914)

- Palpus covered with black hairs; proboscis half as long as head; body 6-6.5 mm long

D. (S.) hervebazini (Parent, 1914)

\section{Discussion}

The subgenera of the genus Diostracus are relatively well defined in the West Palaearctic Region. In the Nearctic, D. mchughi Harmston, 1966 differs from D. prasinus and D. olga Aldrich, 1911 in its bare antennal scape and can be associated with the subgenus Sphyrotarsus, although bearing only two, rather than three pairs of long setae on the scutellum. The borders of the West Palaearctic subgenera become rather obscure in the East Palaearctic and Orient. Saigusa (1984) supposed that most of the species groups proposed in his paper could be raised to the subgeneric rank if a phylogenetic analysis based on all known species were to be carried out. They could have a common ancestor, which is close to Diostracus or Sphyrotarsus, and their real degree of separation (or similarity) may require molecular investigation. Increased sampling effort should provide specimens that are appropriate for future studies of these flies.

Regarding the new species described here, it seems that D. (S.) kustovi sp. nov. is one of the largest hydrophorine species in the Palaearctic Region (see Negrobov 1977-1979). The male body is somewhat longer than the female body $(9.4 v s .7 .0 \mathrm{~mm})$, while wings are approximately equal in length in the two sexes (about $8 \mathrm{~mm}$ ).

\section{Acknowledgments}

The author expresses sincere gratitude to Drs. E.P. Nartshuk and L.A. Kuznetsova (ZIN) for their kindness in furnishing an opportunity to study the collections of their museum. This work was partly supported by grant N 11-04-01051-a from the Russian Foundation for Basic Research to Oleg P. Negrobov. 


\section{References}

Becker T. 1891. Neues aus Süd-Tirol und Steiermark. Ein dipterologischer Beitrag. Wiener Entomologische Zeitung 10: 281-288. http://www.biodiversitylibrary.org/page/11976154\#page/305/ mode/1up

Cumming J.M. \& Wood D.M. 2009. Chapter 2. Adult morphology and terminology. In: Brown B.V., Borkent A., Cumming J.M., Wood D.M., Woodley N.E. \& Zumbado M.A. (eds) Manual of Central American Diptera. Vol. 1: 19-50. Ottawa, NRC Research Press.

Grichanov I.Ya. 2003-2013. A checklist of species of the family Dolichopodidae (Diptera) of the World arranged by alphabetic list of generic names [online database]. Available from http://dolicho.narod.ru/ Genera3.htm [accessed 20 October 2013]

Grichanov I.Ya., Negrobov O.P. \& Selivanova O.V. 2011a. Keys to Palaearctic subfamilies and genera of the family Dolichopodidae (Diptera). CESA News 62: 13-46.

Grichanov I.Ya., Selivanova O.V. \& Negrobov O.P. 2011b. A brief synopsis of Palaearctic genera of the family Dolichopodidae (Diptera). Ukrainska Entomofaunistyka 2 (2): 11-40.

Hesse E. 1933. Sphyrotarsus Parenti n. sp. et les Sphyrotarsus (Diptères - Dolichopodidae) des Alpes françaises. Bulletin Scientifique de Bourgogne 2: 11-20.

Loew H. 1861a. Neue Beiträge zur Kenntnis der Dipteren. Achter Beitrag. Die nordamerikanischen Dolichopodiden. Programme der Königlichen Realschule zu Meseritz 1861: 1-60.

Loew H. 1861b. Beschreibungen einiger neuer europäischer Dipteren. Wiener Entomologische Monatsschrift 5 (11): 348-351. http://www.biodiversitylibrary.org/item/98657\#page/362/mode/1up

Masunaga K. 2000. Two new species of the torrenticolous genus Diostracus Loew (Diptera: Dolichopodidae), with biogeographical notes on the Japanese fauna. Entomological Science 3 (4): 675 685 .

Mik J. 1874. Beitrag zur Dipterenfauna Österreichs. Verhandlungen der Kaiserlich-Königlichen Zoologisch-Botanischen Gesellschaft in Wien 24: 329-354.

Negrobov O.P. 1965. New and little-known species of Dolichopodidae (Diptera) in the fauna of the Soviet Union. Entomologicheskoe Obozrenie 44 (2): 438-446 (in Russian).

Negrobov O.P. 1973. Genera and subgenera of the subfamily Hydrophorinae (Diptera Dolichopodidae) of Holarctic. Zoologicheskii Zhurnal 52 (10): 1514-1520 (in Russian).

Negrobov O.P. 1977-1979. 29. Dolichopodidae, Unterfamilie Hydrophorinae, Unterfamilie Rhaphiinae. In: Lindner E. (ed.) Die Fliegen der Palaearktischen Region 4 (5): 354-530. [29, 316 (1977), 319 (1978), 321-322 (1979): 354-530.]

Negrobov O.P. 1991. Family Dolichopodidae. In: Sóos Á. \& Papp L. (eds) Catalogue of Palaearctic Diptera. Vol. 7. Dolichopodidae-Platypezidae: 11-139. Budapest, Akadémiai Kiadó. http://dx.doi. org/10.1016/B978-0-444-98731-0.50008-9

Negrobov O.P. \& Tsurikov M.N. 1996. A new genus of the family Dolichopodidae (Diptera) from the Caucasus. Zoologicheskii Zhurnal 75 (4): 632-634 (in Russian).

Negrobov O.P., Tsurikov M.N. \& Dzhavelidze I.G. 1988. Materials on the fauna of the family Dolichopodidae (Diptera) of the Lagodekhi nature reserve. In: Voprosy Zashchity Gornykh Lesov [Problems of Mountain Forest Protection] 7: 213-223 (in Russian). Tbilisi, Institute of Mountain Forestry. 
Oldenberg L. 1916. Einige Dolichopodiden meiner Ausbeute (Dipt.). Entomologische Mitteillungen 5 (5/8): 187-198. http://www.biodiversitylibrary.org/item/38722\#page/217/mode/1up

Özdikmen H. 2010. Substitute names for three Palaearctic fly genus group names (Diptera: Limoniidae and Dolichopodidae). Munis Entomology \& Zoology 5 (1): 262-265.

Parent O. 1914. Description de deux Diptères nouveaux du groupe des Dolichopodides. La Fenille des Jeunes Naturalistes 44: 85-86, 108-112. http://www.biodiversitylibrary.org/item/29383\#page/605/ mode/1up

Parent O. 1938. Diptères Dolichopodidés. Faune de France 35: 1-720. Paris, L'Académie des Sciences de Paris.

Saigusa T. 1984. The genus Diostracus from Nepal (Diptera, Dolichopodidae). Bulletin of the Kitakyushu Museum of Natural History 5: 1-74.

Saigusa T. 1995. New species of the genus Diostracus from Eastern Asia (Insecta, Diptera, Dolichopodidae). Bulletin of the Graduate School of Social and Cultural Studies, Kyushu University 1: 73-85.

Saigusa T., Masunaga K. \& Lee C.E. 1997. The genus Diostracus Loew from Korea (Diptera, Dolichopodidae). Esakia 37: 135-140.

Strobl G. 1898. Die Dipteren von Steiermark. IV. Theil. Nachträge zum III. Theil. Mittheilungen des Naturwissenschaftlichen Vereines für Steiermark 34 (for 1897): 192-298. http://www.biodiversitylibrary. org/item/45394\#page/308/mode/1up

Takagi S. 1968. The Dipterous genus Diostracus (Dolichopodidae). Insecta Matsumurana 31: 35-62.

Yang D., Zhang L., Wang M. \& Zhu Y. 2011. Dolichopodidae. Fauna Sinica, Insecta 53: 1-1912 (in Chinese, with English summary). Beijing, Science Press.

Manuscript received: 28 March 2013

Manuscript accepted: 5 August 2013

Published on: 30 October 2013

Topic editor: Koen Martens

Desk editor: Danny Eibye-Jacobsen

Printed versions of all papers are also deposited in the libraries of the institutes that are members of the EJT consortium: Muséum National d'Histoire Naturelle, Paris, France; National Botanic Garden of Belgium, Meise, Belgium; Royal Museum for Central Africa, Tervuren, Belgium; National History Museum, London, United Kingdom; Royal Belgian Institute of Natural Sciences, Brussels, Belgium; Natural History Museum of Denmark, Copenhagen, Denmark. 